\title{
The Kinetics of Langerhans Cells in Equine Insect Hypersensitivity "Kasen”
}

\author{
Tetsuro KUROTAKI*, Kazuya NARAYAMA ${ }^{1)}$, Toshifumi OYAMADA, Hiroyasu YOSHIKAWA and \\ Takashi YOSHIKAWA \\ Department of Veterinary Pathology, School of Veterinary Medicine and Animal Sciences, Kitasato University, Towada, Aomori 034-8628 \\ and ${ }^{1)}$ Narayama Horse Clinic, Nakano, Shizunai, Hokkaido 056-0006, Japan
}

(Received 29 September 1999/Accepted 1 February 2000)

ABSTRACT. An immunohistochemical study was carried out on the kinetics of Langerhans cells (LCs) at various pathological stages of "Kasen". Skin lesions of "Kasen" that were collected by biopsy from May to October were classified histopathologically into three stages: initial (Group I, 31 cases), developing (Group II, 50 cases) and regressing (Group III, 13 cases). LCs showed a positive reaction with antiequine thymocytes (EqT6) monoclonal antibody (MoAb) and anti-major histocompatibility complex (MHC) class II MoAb by immunohistochemical staining. The anti-EqT6 MoAb was intensely positive along the cytoplasmic process. The number of LCs per unit area increased markedly with the passage of time from the initial to the developing stage of the disease, particularly in the epidermo-dermal junction (EDJ). However, the number of LCs tended to decrease in the epidermal layer. In conclusion, the LCs moving into the epidermal layer moved into the EDJ and dermis during the time course of lesion development, and the changes occurring in LCs possibly influenced the progression of the skin lesions of "Kasen".- KEY WORDS: equi ne, i mmunohi st ochemi st ry, i nsect hyper sensi ti vi ty, Kasen, Langer hans cel I.

J. Vet. Med. Sci. 62(6): 561-564, 2000

"Kasen" is a chronic dermatitis that is seen occasionally in horse skin endemically in Hokkaido of Japan [12].

We have pointed out that "Kasen" has the characteristics of Type I and Type IV allergic dermatitis, and that the Langerhans cells (LCs), which are a skin accessory cell, are important in the pathogenesis of "Kasen" [12]. The LCs are bone marrow-derived antigen-presenting cells [17], which have been increasingly recognized as cells that play a major role in skin immunity due to their potent antigen-processing and antigen-presenting abilities $[4,17,19]$. They can be identified readily from their strong expression of major histocompatibility complex (MHC) class II molecules in horses [7, 12]. In addition, CD1a (originally known as T6) is thought to be a useful marker for the demonstration of LCs [18]. This equine T6 (EqT6), which is $49 \mathrm{kDa}$ in molecular weight, was first detected on cortical thymocytes. EqT6 also reacts with a large population of cortical thymocytes from horses [21]. CD1a dendritic cells have been demonstrated in human $[5,8,9,14]$, canine [10] and feline skin $[10,13]$. We clarified that EqT6 ${ }^{+}$dendritic cells were scattered throughout the skin lesions of "Kasen".

In the present study, we focused on the role of LCs in the pathogenesis of "Kasen" lesions.

\section{MATERIALS AND METHODS}

The investigation was conducted on 94 biopsy specimens obtained from 1- to 19-year-old thoroughbred and AngloArabian horses (Table 1). The materials were divided into 3 groups based on the stages of lesions. Group I consisted of 31 animals in the initial stage of "Kasen" disease, which is

CorRespondence to: Kurotaki, T., Research Center for Veterinary Science, The Kitasato Institute, 6-111 Arai, Kitamotoshi, Saitama 364-0026, Japan. characterized by relatively mild histological findings. Group II consisted of 50 animals in the developing stage of "Kasen" disease, which is characterized by marked lesions. Group III consisted of 13 animals in the regressing stage of "Kasen" disease. In addition to our previous samples [12], one was added to cases in the initial stage, and two in the developing stage. Skin samples were collected from three normal animals as normal controls.

The specimens were biopsied using a dermatome from the skin lesions of the tail base, neck and mane with a size of about $1 \mathrm{~cm}^{2}$. These were processed for the preparation of paraffin and cryostat sections. For the paraffin sections, they were fixed as quickly as possible in $10 \%$ neutral buffered formalin, dehydrated in an ascending alcohol series according to the routine method, lucidified with xylol, then embedded in paraffin wax. All sections were cut at a thickness of $4 \mu \mathrm{m}$ and stained with hematoxylin and eosin (HE). For the cryostat sections, they were put on a filter paper, mounted in Tissue-Tek O.C.T. compound (Sakura. Finetechnical, Tokyo, Japan), then frozen rapidly

Table 1. Materials

\begin{tabular}{|c|c|c|c|c|}
\hline \multirow{2}{*}{$\begin{array}{r}\text { Histological } \\
\text { stage }\end{array}$} & \multirow[t]{2}{*}{ Breed } & \multicolumn{2}{|c|}{ Sex } & \multirow{2}{*}{$\begin{array}{c}\text { Age } \\
\text { (means) }\end{array}$} \\
\hline & & $\hat{\delta}$ & 우 & \\
\hline \multirow{3}{*}{ Initial stage } & Thoroughbred & 3 & 19 & 6.5 \\
\hline & Arabian & 1 & 4 & 9.4 \\
\hline & unknown & & 4 & 10.0 \\
\hline \multirow{3}{*}{$\begin{array}{r}\text { Developing } \\
\text { stage }\end{array}$} & Thoroughbred & & 37 & 7.7 \\
\hline & Arabian & & 10 & 7.9 \\
\hline & unknown & & 3 & 12.5 \\
\hline $\begin{array}{r}\text { Regressing } \\
\text { stage }\end{array}$ & Thoroughbred & & 13 & 9.2 \\
\hline Control & Thoroughbred & 1 & 2 & 8.3 \\
\hline
\end{tabular}



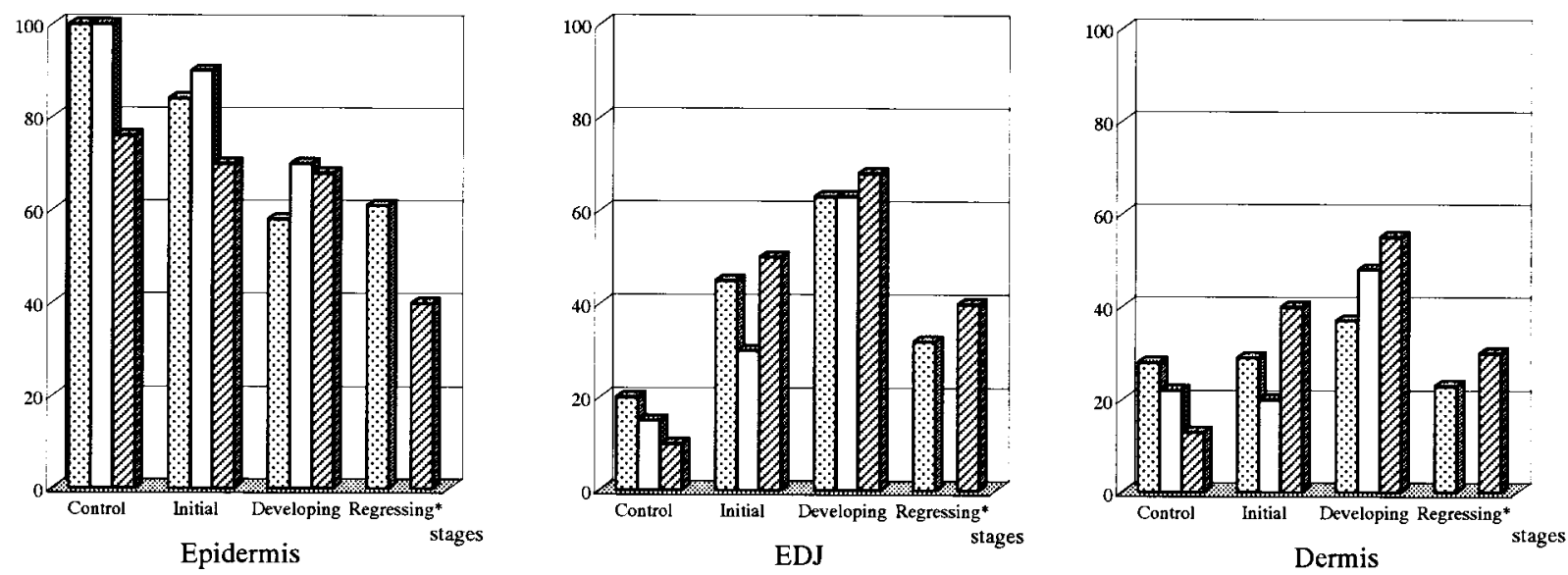

Fig. 1. Numerical value of Langerhans cells shows the number per unit area by HE, anti-EqT6 (T6) and anti-MHC class II (MHC II) staining. $\square$ : HE $\square$ :T6 $\square$ : MHC II. *: no data to anti-EqT6 stain.

in liquid nitrogen for immunohistochemistry. The frozen tissue samples were kept at $-80^{\circ} \mathrm{C}$ until use.

An immunohistochemical investigation was conducted in order to detect the localization of LCs and T lymphocytes. All paraffin and cryostat $(10 \mu \mathrm{m})$ sections were stained by the avidin-biotin-peroxidase complex (ABC) method (Vector Laboratories, U.S.A.). Dewaxed sections were incubated with anti-MHC class II monoclonal antibody (MoAb) (H42A, VMRD, U.S.A.) as the primary sera and biotinated goat anti-mouse IgG (Tago, U.S.A.) as the secondary serum. T lymphocytes were stained with anti-CD2 MoAb (HB88A, VMRD, U.S.A.) and biotinated goat anti-mouse IgG (Tago, U.S.A.) as the secondary serum. Frozen sections were incubated with anti-equine thymocytes MoAb (EqT6, VMRD, U.S.A.) as the primary antiserum, and biotinated goat anti-mouse IgG (Tago, U.S.A.) as the secondary serum. LCs in the whole specimens were counted using an objective lens micrometer. The results shown are the average per 1.59 $\mathrm{cm}^{2}$ of each layer (Fig. 1).

\section{RESULTS}

The histopathological features of "Kasen" have been reported previously [12].

By light microscopy, LCs had a characteristic nuclear membrane with irregular depressions, and broad and clear cytoplasm (Fig. 2). The anti-EqT6 serum was positive throughout the cytoplasm, particularly along the cytoplasmic process (Fig. 3). In contrast, the anti-MHC class II MoAb was homogeneously positive throughout the cytoplasm (Fig. 4).

LCs and a very small number of $\mathrm{CD} 2^{+}$lymphocytes were scattered diffusely throughout the lesion with edematous changes of the epidermal layer at the initial stage of the disease (Fig. 1). LCs were observed to have an irregular nuclear shape with deep basophilic staining, particularly cells from the upper stratum spinous to the intermediate stratum spinous. The epidermo-dermal junction (EDJ) had mild edema, where LCs were distributed sporadically. LCs in the epidermal layer showed a tendency to decrease at the developing stage of the disease compared to the initial stage (Fig. 1). The EDJ was found to have a number of LCs and $\mathrm{T}$ lymphocytes and was characterized by edematous changes, associated with an edematous thickening of the basement membrane. LCs were distributed in large numbers around the vascular and lymph vessels of the dermis. In contrast, lymphocytes were more predominant in the dermis than in the EDJ. Most of these lymphocytes yielded positive results with anti-CD2 MoAb staining. LCs and lymphocytes showed decreases at the regressing stage of the disease in both the epidermal layer and EDJ (Fig. 1). As indicated above, the number of LCs and T lymphocytes in the EDJ and dermis increased markedly, with the occasional formation of several aggregated foci.

\section{DISCUSSION}

In the specimens examined, dendritic cells observed from the upper stratum spinous to the dermis during each pathologic stage stained positively for EqT6 and MHC class II antigens, indicating clearly that they have the characteristics of LCs. LCs of this type were observed occasionally together with $\mathrm{T}$ lymphocytes, particularly in lesions with a marked edematous change from the initial stage to the developing stage of "Kasen" disease. This observation was regarded as a landmark finding of the pathologic state that develops in association with edematous change in that lesion. Furthermore, LCs showed morphologic and numerical changes at each stage of the disease. The number of LCs per unit area increased markedly with the passage of time from the initial to the developing stage of the disease, particularly in the EDJ. However, the number of LCs tended to decrease in the 


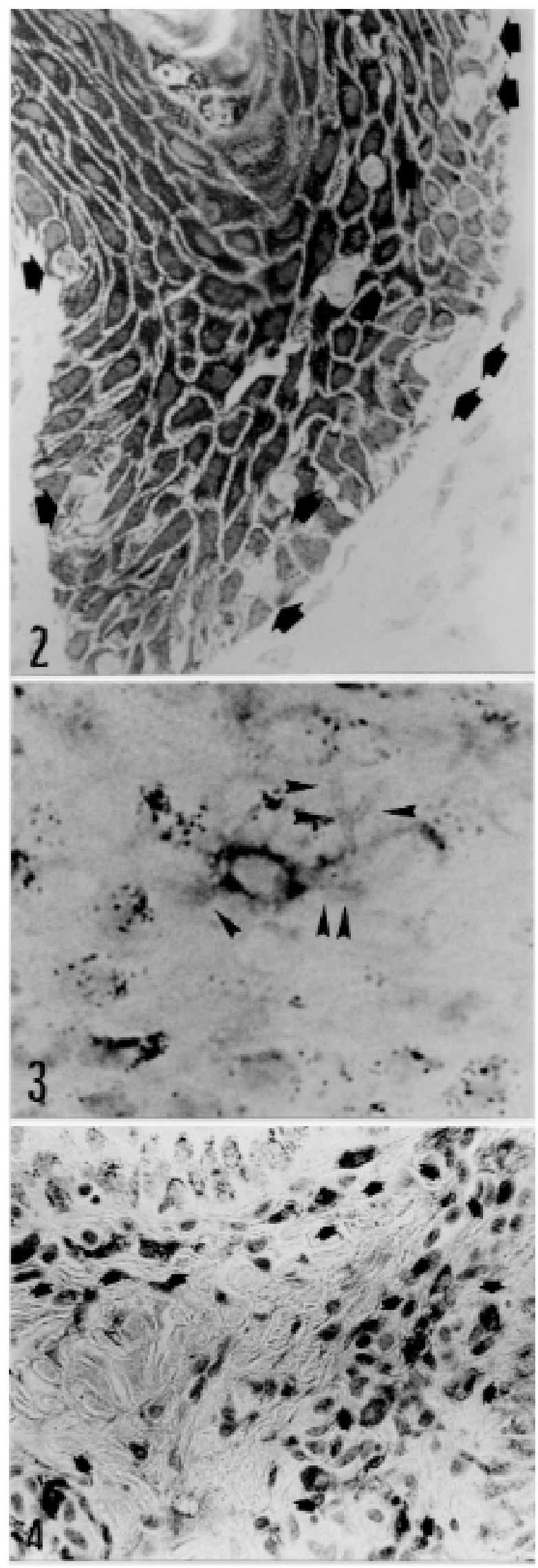

epidermal layer. In the experiment using ferritin, the number of LCs decreased in the epidermal layer at an early stage, but inversely increased in the dermis [16]. It was unlikely in the animals under investigation in the present study that there was a decrease in the absolute number of LCs due to damage and necrosis. Rather, movement of LCs from the epidermal layer toward the dermis appeared to be a more reasonable explanation. In conclusion, LCs moving into the epidermal layer moved into the EDJ and dermis over the course of time. An increase in the number of $\mathrm{T}$ lymphocytes in the EDJ and dermis occurred in parallel with the increase in LCs in the EDJ, further suggesting a close relation between the LCs and T lymphocytes in skin lesions affected by "Kasen". These results clearly suggest that at least at the histological level, type IV allergy play an important role in the development of skin lesions affected by "Kasen" disease. We expressed the number of LCs in terms of positively for EqT6 and MHC class II staining. However, the results were not consistent with those of $\mathrm{HE}$ staining. This was probably because these stainings were not necessarily performed with serial sections.

The skin lesion of "Kasen" disease is very similar to those occurring in disorders such as Queensland itch [15] and sweet itch [1], which are observed in various countries. It has been suggested that these lesions result from Type I and Type IV allergic dermatitis [22]. Allergic contact dermatitis (ACD) is a form of Type IV allergic reaction, and may be considered to consist of two stages [2, 3, 11, 20]. The sensitization phase occurs at the first contact of skin with the hapten. Hapten is taken up by LCs, which migrate from the epidermal layer to the draining lymph nodes, where hapten-specific memory $\mathrm{T}$ lymphocytes develop in the para-cortical area. Microscopically, this phase begins as areas of spongiosis (intracellular edema) that progress to vesiculation and infiltration of the affected epidermal layer by lymphocytes and lesser numbers of neutrophils. After picking up previously encountered haptens in the elicitation phase, LCs make contact with hapten-specific memory $\mathrm{T}$ lymphocytes, which are then able to activate T lymphocytes in the dermis. Microscopically, there may be acanthosis, erosions, and secondary bacterial infection of affected areas due to self-inflicted trauma from licking, biting or scratching. The dermis beneath these areas has variable degrees of superficial, perivascular infiltrates with lymphocytes, LCs and small numbers of eosinophils. The histopathologic findings are also very similar to those of the

Fig. 2. Case No. 54. LCs in skin. Light microscopically, the LCs (arrows) are characterized by an irregularly depressed nuclear membrane, and a broad and lucid cytoplasm. Embedded in epon. Toluidine blue staining. $\times 515$.

Fig. 3. Case No. 80. At the developing stage of the disease. AntiEqT6 $^{+}$LCs with an extension of dendritic processes between spinous cells. Strong reaction with anti-EqT6 mouse MoAb is seen particularly along the cytoplasmic processes (arrowheads). Anti-EqT6 immunostaining. $\times 785$.

Fig. 4. Case No. 46. LCs in EDJ. Uniform reaction with antiMHC class II mouse MoAb can be seen in the cytoplasm (arrows). Anti-MHC class II immunostaining. $\times 323$. 
skin lesion of "Kasen" [12]. However, recent studies demonstrating that corticosteroid- and UV- induced LC depletion paralleled an increase in the ACD, suggested that resident LCs are not the relevant antigen presenting cell (APC) in the elicitation phase of ACD and that they may even provide downregulatory, rather than stimulatory, signals [6]. Whereas epidermal LCs are thought to be the principal APC for initiation of ACD, their role as APC in the elicitation phase of ACD is still unclear.

As mentioned above, the changes occurring in LCs possibly influence the progression of the skin lesions of "Kasen". Other fundamental points of interest that remain obscure are the nature and function of the cytoplasmic structure (Birbeck granules), the effects of various cytokines on LCs and the function and the phenotype of T lymphocytes.

\section{REFERENCES}

1. Baker, K. P. and Quinn, P. J. 1978. A report on clinical aspects and histopathology of sweet itch. Equine Vet. J. 10: 243-248.

2. Becker, D. and Knop, J. 1993. Mechanism in allergic contact dermatitis. Exp. Dermatol. 2: 63-69.

3. Belsito, D. V. 1997. The rise and fall of allergic contact dermatitis. Am. J. Contact Dermatol. 8: 193-201.

4. Bos, J. D. 1997. The skin as an organ of immunity. Clin. Exp. Immunol. 107 (Suppl. 1): 3-5.

5. Fujita, M., Horiguchi, Y., Kashihara-Sawami, M. and Imamura, S. 1988. Langerhans cells in the late phase of allergic contact dermatitis. pp. 405-411. In: The Langerhans Cell (Thivolet, J. and Schmitt, D. eds.), John Libbey Exrotext Ltd., Paris.

6. Grabbe, S., Steinbrink, K., Steinert, M., Luger, T. A. and Schwarz, T. 1995. Removal of the majority of epidermal Langerhans cells by topical or systemic steroid application enhances the effector phase of murine contact hypersensitivity. J. Immunol. 155: 4207-4217.

7. Hamada, M., Takechi, M. and Itakura, C. 1992. Langerhans' cells in equine cutaneous papillomas and normal skin. Vet. Pathol. 29: 152-160.

8. Harrist, T. J., Muhlbauer, J. E., Murphy, G. F., Mihm, M. C. and Bhan, A. K. 1983. T6 is superior to Ia (HLA-DR) as a marker for Langerhans cell and indeterminate cells in normal epidermis: A monoclonal antibody study. J. Invest. Dermatol. 80: $100-103$.

9. Hogan, A. D. and Burks, A. W. 1995. Epidermal Langerhans' cells and their function in the skin immune system. Ann. Allergy Asthma Immunol. 75: 5-10.
10. Jones, T. C., Hunt, R. D. and King, N. W. 1997. The skin and its appendages. pp. 817-897. In: Veterinary Pathology, 6th ed., Williams \& Wilkins, Baltimore, MD.

11. Krasteva, M., Kehren, J., Ducluzeau, M. T., Sayag, M., Cacciapuoti, M., Akiba, H., Descotes, J. and Nicolas, J. F. 1999. Contact dermatitis. I. Pathophysiology of contact sensitivity. Eur. J. Dermatol. 1: 65-77.

12. Kurotaki, T., Narayama, K., Oyamada, T., Yoshikawa, H. and Yoshikawa, T. 1994. Immunopathological study on equine insect hypersensitivity ("Kasen") in Japan. J. Comp. Pathol. 110: 145-152.

13. Marchal, I. S., Dezutter-Dambuyant, C., Willett, B. J., Woo, J. C., Moore, P. F., Magnol, J. P., Schmitt, D. and Marchal, T. 1997. Immunophenotypic characterization of feline Langerhans cells. Vet. Immunol. Immunopathol. 58: 1-16.

14. Ray, A., Schmitt, D., Dezutter-Dambuyant, C., Fargier, M. C. and Thivolet, J. 1988. Fate of CD1a antigens after endocytosis by means of cell synthesis inhibitor (cycloheximide) and ionophore (monensin) in living Langerhans cells. pp. 193203. In: The Langerhans Cell (Thivolet, J. and Schmitt, D. eds.), John Libbey Exrotext Ltd., Paris.

15. Riek, R. F. 1954. Studies on allergic dermatitis ("Queensland itch") of the horse: The aetiology of the disease. Aust. J. Agric. Res. 5: 109-129.

16. Silberberg-Sinakin, I., Thorbecke, G. J., Baer, L. R., Rosenthal, A. S. and Berezowsky, V. 1976. Antigen-bearing Langerhans cells in skin, dermal lymphatics and in lymph nodes. Cell Immunol. 25: 137-151.

17. Staquet, M. J. 1988. Origin and precursors of Langerhans cells. pp. 3-7. In: The Langerhans Cell (Thivolet, J. and Schmitt, D. eds.), John Libbey Exrotext Ltd., Paris.

18. Stingl, G., Hauser, C., Tschachler, E., Groh, V. and Wolff, K. 1989. The immune functions of epidermal cells. pp. 3-72. In: Immune Mechanisms in Cutaneous Disease (Norris, D. A eds.), Marcel Dekker Inc., New York.

19. Streilein, J. W. 1983. Skin-associated lymphoid tissues (SALT). J. Invest. Dermatol. 80: 12s-16s.

20. Teunissen, M. B. M. 1992. Dynamic nature and function of epidermal Langerhans cells in vivo and in vitro: a review, with emphasis on human Langerhans cells. Histochem. J. 24: 697716.

21. Wyatt, C. L., Davis, W. C., McGuire, T. C. and Perryman, L. E. 1988. T lymphocyte development in horses. I. Characterization of monoclonal antibodies identifying three stages of $\mathrm{T}$ lymphocyte differentiation. Vet. Immunol. Immunopathol. 18: 3-18.

22. Yager, J. A. and Scott, D. W. 1993. The skin and appendages. pp. 614-615. In: Pathology of Domestic Animals, 4th ed. (Jubb, K. V. F., Kennedy, P. C. and Palmer, N. eds.) Academic Press, Florida. 